\title{
極限再帰関数における広義計算概念の仕組み
}

\author{
八 杉 滿利子*
}

\section{A Framework for the Extended Notion of Computation Implied by the Limiting Recursive Functions}

\author{
Mariko YASUGI*
}

\begin{abstract}
The halting property as such is not guaranteed for limitimg recursion, since its evaluation process requires infinitely many steps. Nevertheless, as limiting recursive functions are useful in the study of computational aspects of mathematics on the continuum, it is desirable that some extended notion of computation be bestowed upon limiting recursion. We will here present a framework which general recursion and limiting recursion can share in characterizing their functions, and in which the halting property of the former and the identification in the limit of the latter can be expressed in terms of a formula stating a kind of compactness of a sequence of sets. We regard this fact as claiming that limiting recursion is conjunctive to general recursion, and hence can be viewed as a computation in an extended sense.
\end{abstract}

\section{1.はじめに：問題の背景}

本論では、[9] および[10]を引き継ぎ、それらにお いて問題にされた極限再帰 (limiting recursion) が一 般再帰（general recursion）の何等かの意味での自然 な概念拡張であること、あるいは両者が同じ仕組みに 入ること、を説明するための仕組みとそれに必要な一 つの原理を提示する。提示される原理は、極限再帰関 数の定義可能性条件の集合列による表現であり、「有界 性原理」と名づけられる。

問題の背景は「計算可能性」という概念を含む連続 体上の数学研究である(詳細は [8-10]を参照)。その研 究方法は通常の数学となんら変わりない。しかし「計 算可能性」を扱う以上、そこで「計算」と主張される 概念が通常の計算概念または何等かの意味でその接続 上にあることを確認しなければならない。我々の計算 可能性研究では、自然数上の計算論に扔ける再帰関数 の計算可能性を基礎にしている。しかし有意義な数学 の展開のためには、再帰性を超える必要があり、それ

*E-mail: yasugi@cc.kyoto-su.ac.jp
が問題の出発点なのである。

自然数上の計算とは、大筋次のように述べられる一 連の事象である：

（*) 各引数に対して、決定可能な (decidable) プ ロセスが生じ、それがやがて停止し（停止性）、答 え (数值) が産出される。

連続体上の計算可能性理論は、有理数列による実数 の構成や連続関数の連続率などを再帰関数によって支 配することから出発する。そのようにして得られる対 象を計算可能実数、計算可能連続関数、などと呼ぶ。他 方、解析学その他の科学・技術においては多くの不連続 関数が重要な役割を果たす。不連続関数を含む数学の 計算可能な構造については、たとえば関数空間論など により再帰関数を基礎にして扱うことができる（[5,7]） が、その手法では「関数值の評価」は扱えない。実際 に不連続点における関数值を評価しようとすると、一 般に再帰関数を基礎にした計算可能性の枠組みを超え ることが知られている。このために、不連続関数の関 数值の計算に関する理論が、解析学における計算可能 性問題の課題の一つとなる。その課題を扱う手段の一 
つとして、Gold [4]により学習理論のために導入され た「極限再州関数論」が有用である $([8,9])$ 。

極限再帰関数とは再帰関数の極限值（それが存在す るときに）を值とする関数であり、その関数値取得に 至るプロセスは、扔よそ次のように述べられる一連の 事象である：

(**) 各引数に対して決定可能なプロセスが生じ、 それが無限回続く。途中で求める值は出現するが、 無限回のプロセス全体からその值が確定される。

前出の $\left(^{*}\right)$ と比べて、停止性（有限回でのプロセス の終了）が成り立たず、このために極限再帰は通常の 意味の計算とは言いがたいが、それが通常の計算概念 の「自然な拡張であるような仕組み」に入っているか、 を問題にすることはできる。そのような仕組みに入っ ている場合の $(* *)$ のうな事象を仮に「広義計算」と 呼ぶことにする。内容豊富な連続体上の計算可能性理 論の展開のためには極限再帰（またはそれに匹敵する もの）が必要なのであり、我々はその事象を、何らか の基準に従って広義計算として説明することを目指し

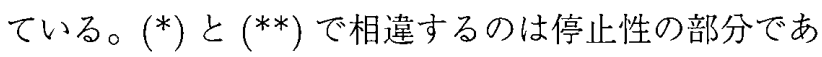
る加ら、これは「広義の意味での停止性概念」を極限 再帰に対して付与することに相当する。

本論ではその根拠を「コンパクト性」という概念に求 める。4 節で詳説するが、コンパクトとは一般に人の 思考あるいは視野に無理なく収まり、内容が豊かな概 念や諸事物を指すものと解釈している。すなわち何等 かの意味で認識が容易であり、かつ有効なものである。 本論の主題は、一般再帰から極限再帰への概念拡張の 接続性を一つの枠組みで表現する試みであり、認識に 関わるものであるので、このようなコンパクト性につ いての考え方を踏まえることは妥当であると考える。

文献 [12]（[11] も参照）では、当該拡張の問題をデ デテントの数学論 [2]（[3] も参照）を基に、概念拡張 の数学的作法に則って説明した。本論では同じ課題を 「計算可能性」についての認識の面から検討しようとい うわのである。

議論を進める前にひとつ用語を設定しておく。以後 「計算」(computation) は実際に計算と認められる、す なわち、所与の決定可能なプロセスから值の取得まで 含奶た事象を計算と呼ぶ。途中経過であるプロセスは 「評価」(evaluation) と呼んで区別する。

次節で極限再帰関数の定義を述べ、その特質および 問題点について一般再帰関数の定義と比較しながら検
討し、以後の各節の紹介をする。

\section{2. 極限再帰関数について}

見易さを考慮して、2引数関数をベースにして説明 する。 2 引数関数 $f$ について、前提条件（極限同定可 能性 : identifiability in the limit)

$$
\forall x \exists y \forall z \geq y . f(x, z)=f(x, y)
$$

のもとで、

$$
h(x)=\lim _{z} f(x, z)
$$

とおく1。ただし式 (2) は略記であって、正式には

$$
\exists y \forall z \geq y \cdot h(x)=f(x, z)
$$

という $f$ と $h$ の関係式が成り立つことを表す。前提条 件 (1) のもとでは (3) を満たす值 $h(x)$ が（各 $x$ につ いて）一意的に定まる。したがって $h(x)$ は関数であ る。このような関数 $h$ の定義の仕方を (2) のように略 記し、極限同定 (identification in the limit) と呼ぶ。

とくに $f$ が再帰関数のときに極限同定 $(2)$ による関数 の定義の仕方を極限再帰 (limiting recursion) と呼び、 関数 $h$ を極限再帰関数 (limiting recursive function) と呼ぶ。

ここで念のために等式内の記法について注意を喚起 して扮きたい。上述のと抢り式 (2) は略式の表現であ る。 $\lim _{z} f(x, z)$ は定義された量を表しているわけで はない。 $\exists y \forall z \geq y . \phi=f(x, z)$ という関係を満たす量 $\phi$ があれば、その $\phi$ を仮に $\lim _{z} f(x, z)$ と表している のである。極限同定可能性 (1) を仮定すれば、そのよ うな量の一意的存在は保証され、したがってその值を $h(x)$ と置くことができるのである。また、その $\lim$ は 連続体上の極限とは意味が異なることを注意しておき たい。

比較のために、一般再帰関数の定義を表示しておく。 再帰関数 $g$ につて前提条件（停止性）

$$
\forall x \exists y . g(x, y)=0
$$

が成り立つとき、

$$
\varphi(x)=\min _{y} . g(x, y)=0
$$

\footnotetext{
${ }^{1} \lim _{z} f(x, z)$ の表現は式 (1)、つまり極限同定可能性が 成り立つときにのみ、使用可能であることに注意。
} 
とおくと $\varphi$ は関数であり、このような関数の定義を一 般再帰と呼ぶ。周知のように、原始再帰関数と再帰的 定義の反復によって得られる関数が一般再帰関数と呼 ばれる。

一般再帰に扔ける停止性を仮に「実効的停止性」と 呼ぼう。対して、極限同定可能性を「広義停止性」と 呼ぶことにする。

極限再帰関数の関数值は極限操作という、再帰関数 よりも強い仕組みにしたがって取得される。この仕組 みを「広義計算の仕組み」として認めるか否かは、個 人の感覚や数学的必要性などに依存するであろう。そ の仕組みを必要とする立場にある筆者の課題は、その 仕組みについて考察し、それが「広義計算」として認 められるべきことの説明を求めることである。

式 (2) が関数值 $h(x)$ の定義を直接与えているもの ではないことに再度注意を喚起したい。この式が示唆 することは、 $f(x, n)$ の評価と $f(x, n)=f(x, n+1)$ ? の判定を $n=0,1,2, \cdots$ と際限なく続け、それらの 操作の無限回の反復が終了したものと想定してそれ を観察し、ある箇所 $N$ 以後のすべての $n$ について $f(x, n)=f(x, n+1)$ ? の答えが肯定になるとき、安 定值 $f(x, N)$ を極限值として $h(x)$ とおくと、 $h(x)$ が 関数になる、という状況である。極限再帰関数の評価 においては、このような無限操作を避けることはでき ない。それのみならず、連続体上の極限と異なり、正 解への近似率の類も一般には不可能である。

以後、3 節で広義計算の仕組みとして「計算設計」と いう枠組みを提案し、一般再帰と極限再帰の計算設計 を示す。計算設計の条件の一つは、評価過程の広義停 止性（「有限 “的”」停止性と呼ぶ）である。その「有 限 “的”」事象の基礎のために、4 節で「コンパクト性」 という考え方を導入する。コンパクトとは、諸事物の 認識のし易さの一つの指標である。そして 5 節でコン パクト性に適う原理として、「集合列の有界性原理」を 提案する。それが極限同定可能性と実効的停止性をと もに表現することを示し、その事実を根拠に、前述の 広義停止性が実効的停止性の自然な（接続的）拡張で あることを主張する。すなわち同じ計算設計という一 つの仕組みのなかで、極限再帰が一般再帰とただ一点 で相違する広義停止性が、実効的停止性からの接続に なっているという主張である。それが極限再帰を広義

2 本論では再帰関数も極限再帰関数もすべて全域的であっ て、部分関数は考慮しない。連続体上の計算可能性研 究に必要な自然数上の関数が全域的だからである。
計算とみなすことの説明になると考える。

6 節でコンパクト性の効用をまとめる。とくにコン パクト性が持つ認識論的な価値と 5 節の考察とを併せ て、コンパクトな計算設計を持つ極限再帰を「広義計 算」として位置づけ得ることを再度確認する。最後の 7 節で追記として、筆者の関連する研究について簡単 に触れる。

なお、本論の目的は極限再帰が計算という概念に自 然に接続している、ということのみを主題にしている のであって、計算とは何か、などの一般論に関わるも のではないことを明言しておきたい。たとえば筆者は、 再帰関数は計算可能であると認め、それを本論の検討 における基盤にしている。また、数学および論理学に おける諸事実はすべて受け入れ、それらを考察の基盤 にしている。

さらに強調しておきたいことは、本論では極限再帰 関数を自然数上の計算可能関数として認めることを提 案するものでは「ない」ことだ。本論の主張は「やが て停止」してその時点で值が取得される $\left(^{*}\right)$ と、無限 回のプロセスを経て值が取得される $(* *)$ が、ある種の 枠組みを共有すること、そしてその枠組みが、極限同 定可能性が（実効的停止性を含む）「広義停止性」を表 すと示唆すること、なのである。

\section{3. 計算設計}

1 節と 2 節で提議された課題に取り組むためには、 考察の対象を明確にしなければならない。そこで言及 された広義計算の仕組みとして、「計算設計」という枠 組みを導入する。以下の条件 $[C]$ を満たす表現 $X$ を 「計算設計」と呼ぶことにする。

条件 $[C]$ は次の 3 項目から成る。

1. $X$ は何らかの明示的な表現である(表現の明晰性)。 2. $X$ のある解釈が、何等かの評価過程 $(X$ の評価モ デルと呼ぶ）を喚起する(実質化可能性)。

3. 2 の評価モデルの何等かの意味の停止性を主張する 「有限“的”」な原理が $X$ から導かれる(「有限 “的”」 停止性)。

本論の目標のために条件 $[C]$ を満たす表現 $X$ を考 察の対象にする理由は、次のと㧍りである。条件 1 は、 考察の対象の明確化のための条件である。表現形式は とくに限定しない。記述が明晰であって、何らかの解 䣋で条件 2 に合う自然な評価過程が生じればよい。条 
件2は1の表現の実質化を意味し、それによって1を 認識の対象にすることに意味が生じる。

条件 3 が本質の部分である。条件 3 では 2 の過程の ある種の停止性を保証する数理的な表現が想定されて いる。その際「有限 “的”」の意味は指定しない。本論 で実際に採用する原理は 4 節でみるように「コンパク 卜性」を有するものである。それは 5 節でみるように 論理式を使って表現される。

上述の事情をまず一般再帰の計算設計で説明しょう。 その後で極限再帰の計算設計を示す。双方のケースで それぞれの関数定義式（定義可能性に関する条件式を 含む）を計算設計とみなし、それらの計算としての解釈 を試みる。双方における関数定義式は明確であり、条 件 1 (表現の明晰性)を満たす。

周知の定義式があるのに、改まって計算設計などと いう概念を持ち込む意味があるのか、と問われるかも しれない。しかし計算設計という一般的な概念を通し てこそ、望まれている広義のケースを含む停止性概念 が統一的に扱えるのである。

一般再帰については、再帰関数 $g$ に関する停止条件 (4) と定義式 $(5)$ の組を $(\varphi$ の) 計算設計とみなすので あり、 $m=0,1,2, \cdots$ について、関数 $g(n, m)$ と等式 の判定 $g(n, m)=0$ ? が (各 $n$ について) 評価過程を 生に゙る (実質化可能性)。関数值 $\varphi(n)$ の取得のために $g(n, m)=0$ ? の肯定的判定を待つ。評価・判定の反復 の長さはあらかじめ決定できないが、反復が実際に停 止上、その正当性が確認可能であり、その時点で $\varphi(n)$ の值が得られることは周知のことである。したがって 停止時点は決定される (実効的・「有限 “的”」停止性)。

このように一般再帰の場合には、2 の評価モデルが有 限の段階で停止し、停止の事実は決定可能である。式 (4) が保証する停止性はその意味で「有限」である。極 限再帰に拡張するときに、「有限“的”」をどのように 解釈するか、が問題なのである。

京お、原始再帰の場合には計算設計の表現から得ら れる情報によって、実際の評価過程を経る前に予め停 止時点を知ることができる。

極限再帰については、再帰関数 $f$ について、1 節で 提示された式 (1) と (2)、すなわち極限同定可能性と 極限同定の定義式の組を $h$ の計算設計とする。極限同 定け評価モデルはおよそ次のようになる（実質化可能 性)。(ここでは $x$ を省略する。)

$f(0), f(1), f(0)=f(1) ?, f(2), f(1)=f(2) ?, \cdots$,

\author{
$f(n+1), f(n)=f(n+1) ?, \cdots$ \\ $\uparrow$ \\ のでの観察 \\ $f(N)=f(N+1)=\cdots \rightarrow$ 出力 $(=h)$
}

前提条件によって「ある有限ステップ $N$ で值が安定 する」という保証があるので、 $f$ の関数值」は $N$ 時 点で確定しているが、事実確認のために、 $f$ の值の計 算と隣接する 2 個の值の比較が反復される。無限回の 計算が必要なので、一般再帰の場合と異なり評価の反 復は有限回ではないが、值の確定場所で「関数值の取 得」という意味の計算が完了しているものと考えるこ ともできる。その意味で関数值の評価は有限段階で停 止しているともみなせる(「有限 “的”」停止性)。今後 の考察ではこの点に焦点を当てる。

なお本論では扱わないが、部分再帰関数は条件 3 を 次のような 3 'に変形して得られる枠組みをもつ。

3'. 2 のプロセスが停止する場合には、その事実が確 認可能である(部分停止性)。

一般再帰関数は当然この条件も満たす。

\section{4. コンパクト性 : 条件 $[C]-3$ へのガイドライン}

極限再帰の評価モデルでは、無限ステップの評価と 無限の彼方での值の決定というイメージのために、有 限的な状況は見えにくい。また「有限“的”」という特 徵づけも難しい。そこで視点を変えて「コンパクト性」 を指標にして再考する。それが条件 $[C]-3$ で要求され る原理への道筋になるからである。

コンパクト性は様々な場面で重要な概念である。そ れは単純化して述べれば、人の思考や視野に無理なく収 まりしかも内容豊かなこと、を意味する。思考の節約 とも関係するだろう。参考のために以下で Raymond [6]による、ソフトウエアに㧍けるコンパクト性の考察 を短く紹介する。（詳しくは[6]の 4 節参照。）それが 一般的な状況でも通用するコンパクト性の概念を的確 に表現しているからである。

「コンパクト性とは、あるデザイン（設計）が人間の 頭脳にフィットするという性質である。熟練したユー ザがマニュアルを必要としないような設計はコンパク トであり、そのときユーザはそれを心地よく使え、よ り生産的になる。しかもコンパクト性は柔軟性に富み、 
また豊かな効果をもたらし得る。」

数学に打けるコンパクト集合はこの精神に調和する ものであるが、コンパクト性は適合範囲が広い概念で ある。必ずしも有限ではない何らかの事物やプロセス が思考の対象として[6]の精神に従うならば、それを 「有限 “的”」とみなすことは妥当であると考える。事 実位相空間に㧍けるコンパクト集合の定義は、任意の 開被覆の中に同機能をもつ有限開被覆が存在すること であるから、「有限 “的”」な特徴づけと言えるだろう。 そしてコンパクト集合については数学的に様々な事実 が証明される、すなわち内容が豊富なのである。

以上の考察を意識しながら、条件 $[C]-3$ の「有限 “的”」 を「コンパクト」で置き換えて考えてみよう。ある計 算設計 $X$ に対して条件 $[C]-3$ で要求される原理の候補 を仮に $Y$ と呼ぶ。その内容がコンパクト性を有する、 という要請を置こう。コンパクトな $Y$ があるときに、 計算設計 $X$ はコンパクトである、ということにする。

$Y$ がコンパクトであるとは、「(熟練した) 関係者の 思考に無理なく収まり、その理解が容易であり、その 使用が快く、豊富な内容をもち、生産的である」など の条件を満たすことである。

コンパクトな対象は一定の範囲に収まるべきもので あるから、原理上無限操作を含む概念も、コンパクト化 されれば理解しやすいようにまとめられるはずである。

コンパクト性には実効的な例も実効的でない例もあ る。可算無限開被覆に対して同機能をもつ有限開被覆 の存在を主張するときに、それが単なる存在命題であ る場合も、所与の無限開被覆からしかる心゙き有限個を 選ぶ具体的な方法がある場合もある。後者のような場 合を実効的コンパクト性と呼ぶことにする。

\section{5. 有界性原理と結論}

以上を参考にして、極限再帰の計算設計を支える原 理を以下のように捉えてみる。ここで採用する原理と は極限再帰関数の計算設計のみに適用されるものでは なく、一般的な概念である。

（集合列の有界性原理）ある集合 $S$ の部分集合列 $\mathcal{C}=\left\{C_{n}\right\}$ が「有界性原理」を満たす、とは、C の 積が、有限個の積で達成されることである：

$$
\exists N . \cap_{n=0}^{\infty} C_{n}=\cap_{n \leq N} C_{n} .
$$

本論の目標のためにこの原理を採用する理由は、式
(6) が $\cap_{n=0}^{\infty} C_{n}$ という無限操作を $\cap_{n \leq N} C_{n}$ という有 界な操作で置き換えることができ、したがって無限操 作で定義される対象 $\cap_{n=0}^{\infty} C_{n}$ が有限操作による対象 $\cap_{n \leq N} C_{n}$ によって認識可能であることを述べているか らである。その意味で (6) はコンパクトな内容をもつ 命題であると見なせる。したがって $[C]-3 に$ における「何 等かの意味の停止性」条件がこのような有界性原理で 表現され得るとき、「有限 “的”」停止性が成り立つも のと認めてよいだろう。

有界性原理を極限再帰関数の計算モデルに適用する ために、所与の $f$ からこの原理が成り立つような集合 列を定義する。簡単のために、再帰的な 1 引数関数 $f$ から定義される極限操作を扱う（2 節の定義を参照）。

極限同定可能性により、 $f$ の極限值の存在は仮定さ れている：

$$
\exists N \forall n \geq N . f(n)=f(N)(=\phi) .
$$

前述のとおり $N$ が特定できないので、極限值 $\phi$ の取得に は無限回の評価 $f(0), f(1), f(2), \cdots$ および $f(n+1)=$ $f(n)$ ? が必要である。

$\mathbf{N}$ を自然数全体の集合ととする。 $n^{*}=\{0,1,2, \cdots, n\}$ とおくとき、 $\mathbf{N}$ の部分集合 $C_{n}, n=0,1,2, \cdots$ を次の ように定義する：

$$
\begin{gathered}
C_{0}:=\mathbf{N}, \\
C_{n+1}:=C_{n} \quad \text { if } \quad f(n)=f(n+1), \\
C_{n+1}:=C_{n} \backslash n^{*} \quad \text { if } \quad f(n) \neq f(n+1) .
\end{gathered}
$$

$(A \backslash B$ は差集合を表す。 $) \mathcal{C}=\left\{C_{n}: n=0,1,2,3, \cdots\right\}$ とおく。C は集合列であり、 $f$ の条件 $(7)$ より有界性

$$
\exists N . \cap_{n=0}^{\infty} C_{n}=\cap_{n \leq N} C_{n}
$$

が成り立つことはは明らかである゙。

（7）と（8）は決定可能とは限らない数 $N$ の存在を主 張している点では類似している。しかし (7) では $N$ 以 上の寸べての $n$ 、寸なわち無限個の $n$ に関する評価の 必要性を明示しているのに対して、(8) は変動する $n$ に関する情報をその都度追うのでなく、 $\cap_{n=0}^{\infty} C_{n}$ とい う 1 個の対象に関して、「 $N$ までの共通部分を考察の 対象にすればよい」と主張している。 $\cap_{n=0}^{\infty} C_{n}$ を直接

${ }^{3}(8)$ の等式に执いてこの列に関しては結果として共通部 分は $C_{N}$ に等しいが、ここでは式 (8)の表現を採用す る。「無限操作の有界操作による置き換え」を強調する ためである。 
認識対象にするのでなく、等式の右辺の有限積を認識 の対象にできる。その意味で、式の理解様式に相違が 生じるのである。

逆に、所与の再帰関数 $f$ について、極限同定可能性 を仮定せずに上記のように集合列 $\mathcal{C}$ を定義したときに、 もしも $\mathcal{C}$ につて有界性原理が成り立つならば、 $f$ に ついて極限同定可能性が成り立つ。以上のように互い に翻訳可能という意味で各 $f$ に関して (7) と (8) は同 等なのである。

$C_{n}$ は次のような意味をもつ。 $C_{n}$ の各要素 $j$ につい て $f(j)$ を極限值 $\phi$ の $(n$-次の) 候補と考えることに すれば、 $n$ の増加とともに候補怔絞られていき、 $\mathcal{C} の$ 有界性は、有限の段階で真の候補にゆきつく、という ことを意味する。共通部分が不変になった段階 $N$ で、 $\cap_{n=0}^{N} C_{n}$ の各要素 $j$ が正しい候補 $f(j)$ 、すなわち求め る值 $\phi$ 与える。

有界性原理自体においては一般に集合列 $\mathcal{C}$ の再归性 は要求されていないが、ここでは $f$ の再帰性により集 合列 $\left\{C_{n}\right\}$ は再帰的であることに触れておく4。

以上により、極限再帰関数の定義における極限同定 可能性が、集合列 $\mathcal{C}$ の有界性という性質に帰着された。 $\mathcal{C}$ の有界性はコンパクト性を有する。すなわち極限再 㷌閣数の值取得について納得するためには、有界な操 作 $\cap_{n \leq N} C_{n}$ の認識（理解）ができればよいのである。 そのことが、「 $f$ 極限同定可能性が計算の (広義) 停 止性を保証する」という認識を可能にする。したがっ て、極限再帰の計算設計 $[C]-3$ に関する要請である「有 限 “的”」停止性が成り立つ、と考えられる。

ここで念のために一言コメントを添える。上で述べ た「帰着」は数学的な事実である。すなわち、極限同 定可能性と有界性原理は（所与の $f$ について）相互に 変搉可能であり、その意味で同值である。数学的・論 理的に同値であるからこそ、一方の考察を他方の考察 で盽き換え可能なのである。そして本論では認識とい う見地から見れば相違が生じることを問題にしている のである。同じ機能をもつ二つのプログラムについて Ravmond の主張する「コンパクト」であるものとそ うでないものとの相違を想像してみると分かりやすい だそう。

極限再帰の場合を模して原始再帰および一般再帰に ついても、(8) を満たす、すなわち有界性をもつ集合列

\footnotetext{
4 集合列 $\left\{C_{n}\right\}$ が再帰的とは、自然数 $p, n$ についての関 係として $p \in C_{n}$ ?が決定可能、ということである。と くに各 $n$ について、 $C_{n}$ は再帰集合。
}

を定義できる。どちらの場合にも $N$ 番目以降は 1 点 集合になるような集合列が定義される。詳細は省略す るが、原始再帰の場合には問題の $N$ が入力值である集 合列から直接決定される。一般再帰の場合には $N$ は予 め決定できないが、各 $n$ について「 $n$ が $N$ の条件を 満たすか？」が決定可能である。双方とも $N$ が決定可 能という意味で「実効的コンパクト性」を有する。そ の意味で (8) は「実効的有界性をもつ原理」と言える。 極限再帰の場合には「 $n$ が $N$ の条件を満たすか?」が 決定可能ではないのである。

以上より本論の目標が得られたことになる。すなわ ち、再帰関数も極限再帰関数も「コンパクトな計算設 計をもつ」(3 節と 4 節) という意味で、同じ仕組みの 中にある。したがって極限再帰は一般再帰の自然な拡 張である、とみなすことができる。

本節最後に、(7)のような式を避けて式 (8) を使用す る理由を繰り返し説明しておきたい。(7) では変動す る $n$ について、各 $n$ ごとの情報しか得られず、全体像 を得るための無限の手続きが明示されている。その意 味で計算設計の条件 $[C]-3$ を説明しきれていない、と 考えられる。その問題を解消するのが (8) であると見 なせることは上述のとおりである。

\section{6. コンパクト性の効用}

多少重複にもなるが、ここで前節までの論点を振り 返りまとめておきたい。式 (1) あるいは (7) と式 (8) が（ $f$ が与えられたときに）互いに翻訳可能という意 味で数学的に同值であることは、5 節で述べた。本論 の目的は、極限同定可能性に代わる数学的あるいは論 理的に弱い原理を求めることでは「なく」、同值な書き 換えによって認識論的にその価值を認めやすくすると いう試みなのである。そのためにコンパクト性を有す る「有界性原理」に到達したのであった。すなわち、3 節の条件 $[\mathcal{C}]-3$ の「有限 “的”」を「コンパクト」と解 釈するときに、(7) から (8) への書き換えが有効に㗢 く、ということを示そうという試みである。

(7) と (8) は双方とも決定可能とは限らない数 $N$ の 存在を主張している。その $N$ について、(7) では $N$ 以 上のすべての $n$ に関する考察の必要性を明示している のに対して、（8）は本来求めるべき左辺の無限操作の 産物の代わりに「 $N$ までの共通部分を考察の対象にす ればよい」とだけ主張しており、 $N$ の役割の表示に相 異が生じている。(7) は $[\mathcal{C}]-2$ の評価モデルを引き起こ 
すが、その形のままでは無限プロセスのイメージが前 面に出てしまう。その意味で (7) はコンパクトという 指標に直接結びつかない。(8)の形にしてはじめてコ ンパクト性に沿った表現を得る。

本論は自然数上の関数について、計算論における厳 密な停止性ではなく、連続体上の数学の計算可能性研 究の基礎に有効な概念を求めている。計算論において は、仮想にしろ機械的なプロセスが想定されており、そ のプロセスが有限回で終了して值が決定される場合に （全域的な）計算可能関数を与えるとされている。他方 人間の知的機能は機械よりはしなやかであろう。たと えば、我々は再帰関数や極限再帰関数の定義式群を見 て、その評価プロセスを想像できる。また有界性原理 (6)のような数学的な原理の理解から値取得を汲み取 ることもできる。それゆえ撖密な機械的な定義の停止 性でなくても、コンパクトという「有限“的”」な停止 性概念も使用可能なのである。

5 節では、1 節の式群 $(1)$ （または (7)）と (2)を計 算設計とみなし、それらが「広義計算」を表現してい ると考えられることの説明を試みた。まず観察の対象 を計算設計とした（3 節を参照)。それは記号も駆使し た正確な表現である。計算設計が呼び起こす評価モデ ルは自然なものであるが、5 節でも述べたように、極 限同定に由来する無限のイメージを必要とするために、

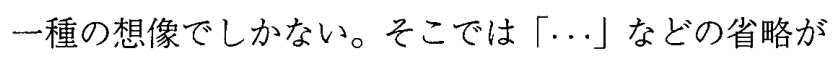
あり、無限遠点での值の取得という物語的な表現しか できない部分もある。無限プロセスは人間の想像力の 豊かな可能性を示しているとともに、一定の思考の範 囲に収まらないものでもある。またそれは、説明しき れない省略などにより、コミュニケーションに不都合 でもある。これらの不都合の解消のために筆者は問題 の抽象化を行い、コンパクト性を有する有界性原理に 到達したのであった。

コンパクト性は有界性、無理のなさ、分かりやすさ、 等の特性を有する。改めて有界性原理を観察すれば、 その特性は集合列の無限積の有限積による置き換え可 能性という、「思考のコンパクト化」あるいは「思考の 節約」卓をもたらすものであることが分かる。

5 ここでの「思考の節約」は、いわゆるオッカムの剃刀 の意味とは異なり、[6] で試みられているような内容を 意味する。

\section{7. 追記}

筆者は、連続体上の計算可能性研究に際して筆者およ び共同研究者等の採用した三種の方法について、[9]〜 [14]で検討してきた。とくに[12]では、数学における 概念拡張の妥当な様式として、デデキントの [2]（[3] も参照)の数学論を採用し、「同質性原理」（[14] では 「接続性原理」と改名）と名付けた三個の条件を提案し た。それらはその概念拡張が、内的必要性から生じる こと、内容的（実質）保存性抒よび法則（形式）保存性 を有すること、である。[13] と [14] ではさらにブルバ キの [1] および Pour-El \& Richards の [5] の数学論を 採用し、同質性原理に構造理論的な解䣋を与えた。こ の二つの様式により、我々の採用した三種の手法の妥 当性を説明した。1 節でも触れたように、それらは数 学における概念拡張の作法に則るものであった。

しかし本論では三種の方法の一つである、極限再帰 関数による手法の妥当性を、より「計算」の意味に即 した仕組みで考察し、その仕組みが「コンパクトであ る」ゆえに、その内容の認識が容易であることの説明 を試みた。それが計算設計と名付けられたものであり、 その条件の一つを集合列の有界性という原理で特徽づ けた。有界性原理はコンパクト性を有すると認められ るからである。

コンパクト性を採用したのは、それが既出のように 「有限“的”」な性質だからである。コンパクトという 概念は [6]の紹介でも見たように、認識論的な意味を もつ。コンパクト性という概念に焦点を当てるならば、 本論の極限再帰の広義停止性を表現する「集合列の有 界性」は、その意味ある一例であるといえる。

最後にもう一度極限同定可能性と有界性原理に戻る と、どちらも $N$ は決定可能ではない。しかし $N$ の存 在という仮定の元で比較すれば、前者は式でしか理解 できず、 $n$ は無限に動くという内容である。後者では内 容不明確ではあっても一つの塊を有限積で理解すれば よく、動くものがない。数学的には相互に翻訳可能で あるが、認識論的には相違がある、ということである。

\section{文献}

[1] Nicholas Bourbaki, The Architecture of Mathematics, The American Mathematical Monthly, Vol.57, No.4 (1950), Mathematical Association of America, 221-232. 
[2] Julius Wilhelm Richard Dedekind, Über die Einführung neuer Funktionen in der Mathematik, delivered as an Habilitationsvorlesung in Göttingen on 30 June 1854; first published in Dedekind Gesammelte mathematische Werke 1932, vol. III, 428-438.

[3] Julius Wilhelm Richard Dedekind, On the introduction of new functions in mathematics, From Kant to Hilbert, A Source Book in the Foundations of Mathematics vol. II (1996), edited by William B. Ewald, Clarendon Press, Oxford, 754-762.

[ 4 ] E. Mark Gold, Limiting recursion, Journal of Symbolic Logic, Vol.30, No.1 (1965), 28-48.

[5] Marian B. Pour-El and Jonathan I. Richards, Computability in Analysis and Physics, SpringerVerlag, 1989.

[6.] Eric Steven Raymond, The Art of Unix Programming, Pearson Education Inc., 2003: On-line version at http://www.faqs.org/docs/artu/index.html

[7] Mariko Yasugi and Masako Washihara, Computability structures in analysis, Sugaku Expositions (AMS), Vol.13 (2000), 215-235.

[8] Mariko Yasugi, Vasco Brattka and Masako
Washihara, Computability aspects of some discontinuous functions, Scientiae Mathematicae Japonicae (SCMJ) Online, Vol.5 (2001), 405-419.

[9] 八杉満利子, “不連続関数の極限計算可能性一意義と問 題点—”, 科学基礎論研究 Vol.30, No.2 (2003), 13-18.

[10]）杉満利子, “連続体上の計算概念について一再帰関数 を超えるもの一”, 哲学論叢 XXXV (2008), 京都大学 哲学論叢刊行会編, 199-209.

[11] 八杉満利子, “数学における概念拡張の仕組み一デデキ ントの研究計画に沿って—”, 哲学論叢 XXXIX (2012), 京都大学哲学論叢刊行会編, サーベイ論文集, 24-35. http://hdl.handle.net/2433/173632

[12] 八杉滿利子，“デデキントの数学観一大学教授資格取 得講演における概念拡張の仕組み一”，哲學研究 596 (2013)，京都哲學会，24-45.

[13] 八杉滿利子, “数学における概念拡張の二つの様式”, 学 位論文 (2014), 京都大学文学研究科哲学専修, 1-159.

[14] 八杉滿利子, “数学理論における接続的概念应張一二つ の様式一”, 哲學研究, 京都哲學会 599, 掲載予定.

(2010 年 1 月 25 日投稿、 2010 年 8 月 1 日再投稿、 2015 年 1 月 25 日再々投稿、 2015 年 2 月 2 日掲載決定) 